\title{
'Climatic factors control rodent seed predation in Pinus pinea L. stands in Central Spain'
}

\author{
Rubén Manso • Marta Pardos • Rafael Calama
}

24 March 2014

\begin{abstract}
- Context Pinus pinea L. presents serious problems of natural regeneration in managed forest of Central Spain. The species exhibits specific traits linked to frugivore activity. Therefore, information on plant-animal interactions may be crucial to understand regeneration failure.

- Aims Determining the spatio-temporal pattern of $P$. pinea seed predation by Apodemus sylvaticus L. and the factors involved. Exploring the importance of $A$. sylvaticus $\mathrm{L}$. as a disperser of $P$. pinea. Identifying other frugivores and their seasonal patterns.

- Methods An intensive 24-month seed predation trial was carried out. The probability of seeds escaping predation was

Handling Editor: Erwin Dreyer

Contribution of the co-authors Rafael Calama: experiment designer, he played an essential role in experiment installation, data collection, article organization and, especially, statistical support

Marta Pardos: project coordinator, she also participated in experiment installation, data collection and article supervision and reviewing.
\end{abstract}

Executive summary Predation of $P$. pinea seeds by $A$. sylvaticus strongly reduces seed availability for natural regeneration. However, dry periods and seed abundance control predation rates. These findings can help managers to design new strategies to enhance regeneration of P. pinea stands.

Electronic supplementary material The online version of this article (doi:10.1007/s13595-014-0396-y) contains supplementary material, which is available to authorized users.

R. Manso · M. Pardos · R. Calama

Departamento de Selvicultura y Gestión de Sistemas Forestales

INIA-Forest Research Center, Ctra. La Coruña km 7.5,

28040 Madrid, Spain modelled through a zero-inflated binomial mixed model. Experiments on seed dispersal by A. sylvaticus were conducted. Cameras were set up to identify other potential frugivores. - Results Decreasing rodent population in summer and masting enhances seed survival. Seeds were exploited more rapidly nearby parent trees and shelters. A. sylvaticus dispersal activity was found to be scarce. Corvids marginally preyed upon $P$ pinea seeds.

- Conclusions Survival of $P$. pinea seeds is climate-controlled through the timing of the dry period together with masting occurrence. Should germination not take place during the survival period, establishment may be limited. A. sylvaticusmediated dispersal does not modify the seed shadow. Seasonality of corvid activity points to a role of corvids in dispersal.

\section{Introduction}

Frugivore behaviour plays a key role in plant distribution and demography (Herrera 1995; Janzen 1970; Jordano 1992), ultimately even conditioning species persistence (Andersen 1987; De Steven 1982; H u ne 1997). In addition, the spatial pattern of seed predation and habitat preference for seed hoarding is known to modify primary seed shadow and the spatial arrangement of recruitment (Schupp 1995; Sch up pa nd Fuentes 1995). Furthermore, differences in hoarding habits (scatter-hoarding vs larder-hoarding) may impact seed germination and seedling establishment.

Many Mediterranean species present large seeds, a highly aggregated seed shadow or a masting habit (e.g. Gómez et al. 2003; González-Rodríguez and Villar 2012). These traits are 
often associated with animal activity, either seed predation or dispersal (Sork 1993). Specifically, processes of seed limitation in natural regeneration due to predation are common in the Mediterranean area (Castro et al. 1999; Gómez et al. 2003, 2008; Hulme 1997). In this respect, Pinus pinea L. is a masting, large-seeded species widely distributed throughout the Northern Mediterranean basin, including Spain. One of the most extensive Spanish P. pinea woodlands is located in the Northern Plateau, where the species occurs naturally. Severe droughts, extreme temperatures and sandy soils are characteristic of the Northern Plateau. The ecological value of $P$. pinea is particularly high since it is able to persist under these severe conditions. Given the commercial importance of its edible seeds, $P$. pinea forests have been managed since the nineteenth century. However, although seed harvesting restrictions are imposed to favour seed rain, natural regeneration rarely succeeds (Calama and Montero 2006). This failure may be explained by the following: masting habit and lack of synchrony with regeneration fellings (Calama et al. 2011; Manso et al. 2012); the species' gravity-based seed dispersal strategy, resulting in patchy seed distribution in managed, open stands (Manso et al. 2012); and a narrow range of adequate climatic conditions for germination, which determines a low probability for seedling establishment in the long term (Manso et al. 2013b). However, the impact of plant-animal interactions on regeneration remains unknown.

In this respect, it is important to fully understand the main relationships between $P$. pinea and the wood mouse (Apodemus sylvaticus L.). A. sylvaticus is a Pan-European and North African generalist rodent central to the exploitation and depletion (and to some extent, the dispersal) of seed crops in different Mediterranean species (Gómez et al. 2003, 2008; Puerta-Piñero et al. 2010). Several factors might determine the pattern of seed predation by A. sylvaticus. First, rodent demographic dynamics: periods with water availability favour wood mouse reproduction (Díaz et al. 2010). During these periods, the pressure exerted over the existing resources may significantly intensify. Second, rodent activity increases in the proximity of seed sources (trees) and shelters. This implies higher predation rates at these locations. In the case of seed sources, rodents are attracted by the higher density of seeds clumping nearby parent trees (distance dependence; Janzen 1970). Concerning shelters, rodents often prefer protected locations when foraging (Hulme 1997). Third, the occurrence of mast years in $P$. pinea boosts food availability in a short period of time. This food surplus may satiate predators, reducing the probability of remaining seeds being exploited (satiation hypothesis; Janzen 1974; Salisbury 1942).

Overall, our main objectives were (1) to determine the pattern of $P$. pinea seed predation by $A$. sylvaticus and the factors driving the process, (2) to explore the potentiality of A. sylvaticus as animal-mediated dispersal of $P$. pinea and (3) to identify other animal species interacting with $P$. pinea and their seasonal relative relevance compared to A sylvaticus. We hypothesized (1) that dry periods and mast pulses control the temporal pattern of predation of $P$. pinea seeds by A. sylvaticus, (2) that predation is more intense nearby seed sources and shelters, (3) that $A$. sylvaticus does not act as an effective disperser of $P$. pinea and (4) that corvids are common, although less relevant $P$. pinea-related frugivores.

In order to fulfil these aims, a 2-year trial was set up in the Northern Plateau. The spatio-temporal pattern of seed removal by $A$. sylvaticus was assessed. The fate of seeds dispersed by A. sylvaticus in burrows/shelters or to superficial locations was investigated. Finally, a camera survey was carried out to identify the species foraging on $P$. pinea seeds and to compare their impact to that of $A$. sylvaticus. Data were analyzed through different techniques, including a zero-inflated modelling approach.

\section{Material and methods}

\subsection{Study site}

The study site is located in two managed $P$. pinea forests on the flats of the Northern Plateau in the municipalities of La Pedraja and Nava del Rey (Online Resource 1) at a mean altitude of $700 \mathrm{~m}$ a.s.1. The study was conducted in two mature even-aged stands at each location (differing in their respective densities as shown in Table 1), where restrictions exist on cone collection for commercial purposes and where regeneration fellings have commenced. The climate is continentalMediterranean with mean monthly temperatures ranging from $4.0^{\circ} \mathrm{C}$ in January to $21.7^{\circ} \mathrm{C}$ in July. Mean annual precipitation is $435 \mathrm{~mm}$, including a period of summer drought (July to September, mean precipitation of $66 \mathrm{~mm}$ ). Soils in this area are highly sandy.

Climatic data were obtained from two meteorological stations located at 15 and $6 \mathrm{~km}$, respectively, from both forests and at the same altitude $\left(41^{\circ} 17^{\prime} \mathrm{N}, 4^{\circ} 40^{\prime} \mathrm{W}\right.$ and $41^{\circ} 29^{\prime} \mathrm{N}, 4^{\circ}$ $59^{\prime} \mathrm{W}$; data available in www.inforiego.org).

\subsection{Experimental design}

A $60 \mathrm{~m} \times 80 \mathrm{~m}(0.48 \mathrm{ha})$ sample plot was set up in each stand in November 2008 (P1 and P2, La Pedraja; N3 and N4, Nava del Rey). A 7.5-m buffer area was included around each plot. All trees and stumps within the plots were mapped and their relative coordinates within each plot calculated.

\subsubsection{Seed removal patterns}

A trial consisting of 64 seed points deployed throughout the four plots ( 16 seed points per plot) was conducted. Seed point location was set such that a wide range of distances among 
Table 1 Summary of stand features

\begin{tabular}{llllcr}
\hline Area & Plot & Coordinates & Ns $\left(\mathrm{ha}^{-1}\right)$ & $\mathrm{BA}\left(\mathrm{m}^{2} \times \mathrm{ha}^{-1}\right)$ & Dg $(\mathrm{cm})$ \\
\hline $\mathrm{P}$ & 1 & $41^{\circ} 28^{\prime} \mathrm{N} 4^{\circ} 43^{\prime} \mathrm{W}$ & 48 & 9.76 & 50.9 \\
$\mathrm{P}$ & 2 & $41^{\circ} 27^{\prime} \mathrm{N} 4^{\circ} 43^{\prime} \mathrm{W}$ & 155 & 18.80 & 40.0 \\
$\mathrm{~N}$ & 3 & $41^{\circ} 26^{\prime} \mathrm{N} 5^{\circ} 3^{\prime} \mathrm{W}$ & 87 & 7.65 & 33.4 \\
$\mathrm{~N}$ & 4 & $41^{\circ} 27^{\prime} \mathrm{N} 5^{\circ} 2^{\prime} \mathrm{W}$ & 60 & 7.04 & 8.6 \\
\hline
\end{tabular}

$P$ Pedraja de Portillo forest, $N$ Nava del Rey forest, $N s$ stand density, $B A$ basal area, $D g$ quadratic mean diameter, $H$ average height

seed points and their closest trees and stumps were represented. The range of distances varied from 0 to $5.60 \mathrm{~m}$ in the case of trees and from 0 to 9.40 concerning stumps. Seed points were protected with a $40 \mathrm{~cm} \times 40 \mathrm{~cm} \times 15 \mathrm{~cm}$ cage made of hard wire mesh (span $4 \mathrm{~cm} \times 4 \mathrm{~cm}$ ) to exclude other possible predators/dispersers. From Jan 2009 to Mar 2011, 50 sound seeds collected from a nearby stand were placed at each seed point at the beginning of each month. The number of seeds removed was recorded monthly, and intact seeds were eliminated.

\subsubsection{Dispersal activity}

A first seed fate experiment was carried out in one plot per stand. For this purpose, 240 seeds were tagged using a $5-\mathrm{cm}$ steel wire with a $2 \mathrm{~cm} \times 1 \mathrm{~cm}$ white plastic label attached to its end. A unique code was printed on each label so that the seeds were individually identifiable. The pine nuts were previously immersed in water for $8 \mathrm{~h}$ and then dried at room temperature to permit partial opening of the shell. The free end of the wire was bent and glue-sealed to the seed through the opening in the kernel. In previous tests, rodents had not shown a significant preference for untreated seeds. Tagged seeds were systematically deployed in groups of 20 seeds throughout the two selected plots ( 6 groups per plot). After 10 and 20 days from placing the seeds, the surroundings of each seed group were checked for labelled seeds up to a distance of $20 \mathrm{~m}$. The experiment was then revisited monthly until either emergence or seed depletion occurred. A first lot of seeds was released on $11 \mathrm{Dec} 2009$. An extraordinary snow event prevented us from revisiting the experiment for over a month, and therefore, we set up a second lot of tagged seeds on 19 Jan 2010. The pine nuts were classified into the following categories according to seed fate: predated in situ, removed and left intact on the soil surface, removed and buried, intact at original position or missing. Where seeds had been removed, the distance from the points of seed release was measured and recorded.

A second seed fate experiment was conducted in the same plots. In December 2009, 12 artificial shelters (Online Resource 2) were deployed in the vicinity of 12 out of the 16 seed predation points of the seed removal experiment (range 1-12.5 m) in the two plots (overall 24 shelters). The minimum distance from one shelter to another was $20 \mathrm{~m}$.
Shelter location represented four levels of a spatial factor describing the positions relative to stumps and seed points, with three replications each (shelters placed at the following: (1) $>5 \mathrm{~m}$ from a stump and $>5 \mathrm{~m}$ from a seed point; (2) $>5 \mathrm{~m}$ from a stump and $<5 \mathrm{~m}$ from a seed point; (3) $<5 \mathrm{~m}$ from a stump and $>5 \mathrm{~m}$ from a seed point; and (4) $<5 \mathrm{~m}$ from a stump and $<5 \mathrm{~m}$ from a seed point). The artificial shelters consisted of $25 \mathrm{~cm} \times 15 \mathrm{~cm} \times 15 \mathrm{~cm}$ boxes made of wood, in which a 5$\mathrm{cm}$ diameter hole had been opened in the front side to permit rodent access. From Jan 2010 to Jan 2011, all the pine nuts released each month at the 12 selected seed removal points ( 7,800 seeds) were individually numbered on the kernel using an indelible pen. The artificial shelters were revisited monthly, and seeds as well as empty shells (assumed predated) found within were counted. The number printed on the nutshell, if any, was recorded to identify the seed point of origin. Empty nutshells were removed, whereas surviving seeds were left in the shelters to be tracked the following month.

\subsubsection{Frugivore identification}

A self-activating HCO ScoutGuard SG550 camera, baited with pine nuts, was installed at each plot. The devices were placed approximately $30 \mathrm{~cm}$ above ground level. The cameras were equipped with an infrared flash allowing night recording. They were programmed to capture $20 \mathrm{~s}$ of video. The time elapsed between consecutive videos was set to $3 \mathrm{~min}$ to prevent multiple recordings of the same visit. Recorded material was downloaded and reviewed monthly, discarding false detections and poorly captured videos. Visiting animals were identified at a specific level.

\subsection{Data analysis}

\subsubsection{Seed removal patterns}

It is expected that seed removal data exhibit a zero-inflated distribution (zero counts exceeding those expected at random). In order to deal with such a distribution, we modelled seed removal through a zero-inflated binomial model (Hall 2000). This approach combines a binomial and a Bernoulli distribution. The first distribution acts at seed point level and it is used to model the probability $\pi$ of all seeds being removed 
from a seed point. The second distribution models the probability $p$ of a single seed remaining at a seed point (seed level) given that any seed remained. Simultaneous estimation of parameters defining both processes is attained through the maximization of the corresponding likelihood function. The logit link function was used to connect $\pi$ and $p$ to linear terms of covariates. Different covariates were used in order to test the effect of the main factors thought to affect seed removal:

Demographic stage Cumulative precipitation over the 3 months prior to each survival recording $\left(\mathrm{Pp}_{-3}\right)$ was tested, as a surrogate of resource availability and, in turn, of rodent population (Díaz et al. 2010). We also included the monthly drought $(D)$ to take into account the extreme summer conditions of the Northern Plateau. This variable was assessed as the difference between the potential evapotranspiration and the actual maximum evapotranspiration of month $l$ (Gandullo 1994; Thornthwaite and Mather 1957).

Spatial location of stand elements The influence potential of all trees (IPOT $t$ ) and stumps (IPOTs) located within an influence area of a 15-m radius from seed points was calculated for each seed point and included as covariates in the model. IPOT is a competition index based on the concept of ecological field theory (Wu et al. 1985), empirically modified by Kuuluvainen and Pukkala (1989):

$\mathrm{IPOT} t_{j}=1-\mathrm{GPOT} t_{j}$, where GPOT $t_{j}=\prod_{t=1}^{N t_{j}}\left(1-I_{t j}\right)$ and

$$
I_{t j}=I_{t j}(0) \times \exp \left(-b \cdot d_{t j}\right)
$$

$\operatorname{IPOT}_{j}=1-\mathrm{GPOT}_{j}$, where GPOT $s_{j}=\prod_{s=1}^{N s_{j}}\left(1-I_{s j}\right)$ and

$$
I_{s j}=\exp \left(-b \cdot d_{s j}\right)
$$

$I_{t j}$ and $I_{s j}$ are the potential influence of tree $t$ or stump $s$ at seed point $j, d_{i j}$ and $d_{s j}$ are the distances from tree $t$ or stump $s$ to seed point $j, I_{t j}(0)$ is $\mathrm{dbh}_{t j} /\left(\max \mathrm{dbh}_{t}\right.$ at each plot $), \mathrm{dbh}_{t j}$ is the diameter at breast height of tree $t$ in the seed point $j$ influence area, $b$ is a parameter assumed to equal 0.4 , and $N t_{j}$ and $N s_{j}$ are the number of trees and stumps in the seed point $j$ influence area. IPOT ranges from 0 (no competition) to 1 (maximum competition).

Masting events The mean monthly weight of cones borne by trees $\left(N_{0}\right.$, in $\mathrm{kg} \mathrm{ha}^{-1}$ month $\left.^{-1}\right)$ was used as an explanatory variable at stand level. Seed production for all four plots was predicted by means of the model by Calama et al. (2011). The beginning and length of the dispersal period were assessed using the model by Manso et al. (2012). The covariate entered the model as a two-order polynomial (sensu Juliano 2001). The sign and significance of the corresponding parameters indicate the type of rodent response to varying seed production, according to Holling (1959a, b).
The evaluated expression of the two parts of the model is as follows:

$$
\begin{aligned}
\log \left(\pi_{j k l} /\left(1-\pi_{j k l}\right)\right)= & \beta_{0}+\beta_{1} N_{0}+\beta_{2} N_{0}^{2}+\beta_{3} D_{l} \\
& +\beta_{4} P p_{l-3}+\beta_{5} \mathrm{IPOT}_{j k}+\beta_{6} \mathrm{IPOT} s_{j k}
\end{aligned}
$$

$$
\begin{aligned}
\log \left(p_{i j k l} /\left(1-p_{i j k l}\right)\right)= & \gamma_{0}+\gamma_{1} N_{0}+\gamma_{2} N_{0}^{2}+\gamma_{3} D_{l} \\
& +\gamma_{4} P p_{l-3}+\gamma_{5} \text { IPOTt }_{i j k}+\gamma_{6} \text { IPOTs }_{i j k}
\end{aligned}
$$

where $i, j, k$ and $l$ are the indices denoting seed, seed point, plot, month and year levels, respectively, and $\beta_{0-6}$ and $\gamma_{0-6}$ are vectors of unknown but predictable parameters related to the aforementioned set of covariates.

Given the sampling scheme, the assumption of error independence may not hold. Correlation was taken into account through a mixed-model approach. Random effects at plot $j$, seed point $k$ and/or year $m$ levels, as well as their interactions, were included as intercept linear terms $u$ and $v$ in Eqs. 1 a and $1 b$, respectively. Random effects were assumed to be normally distributed, with a mean zero and variance-covariance matrix to estimate. Due to computing limitations, the levels of random effects were tested separately. The final models were evaluated in terms of Akaike Information Criterium (AIC).

Model accuracy was evaluated by comparing predicted $\left(\widehat{y}_{j k l}\right)$ and observed $\left(y_{j k l}\right)$ values of remaining seeds. Mean error $(E)$, root mean squared error (RMSE) and modelling efficiency (EF) of the selected conditional model were calculated (Eqs. 2a, 2b and 2c):

$E=\frac{\sum_{j k l}\left(y_{j k l}-\widehat{y}_{j k l}\right)}{n}$

$\mathrm{RMSE}=\sqrt{\frac{\sum_{j k l}\left(y_{j k l}-\widehat{y}_{j k l}\right)^{2}}{n-1}}$

$\mathrm{EF}=1-\frac{\sum_{j k l}\left(y_{j k l}-\widehat{y}_{j k l}\right)^{2}}{\sum_{j k l}\left(y_{j k l}-\bar{y}_{j k l}\right)^{2}}$

Given that $E$ only provides information on the mean bias, further bias diagnosis was carried out. A regression between observed and predicted values of the type $y_{j k l}=\delta_{0}+\delta_{1} \widehat{y}_{j k l}$ (sensu Sagnard et al. 2007) was computed as a measure of the 
level of concordance between data and model. The null hypothesis of $\delta_{0}=0$ and $\delta_{1}=1$ (implying a successful fit) was evaluated using a simultaneous $F$ test (Montgomery et al. 1992). Furthermore, observed and predicted values were averaged by measurement period at plot level and then graphically compared to test the ability of the model to account for pure temporal variability.

All calculations were done using PROC NLMIXED in SAS (version 9.2.)

\subsubsection{Dispersal activity}

Polar coordinates from deployment location of all recovered seeds were recorded on each revisiting date of the first fate experiment. Seed fate was classified according to the categories described in Subsection 2.2. This descriptive analysis also included the proportion of recovered seeds and proportion of destroyed seeds. In the second seed fate trial, a generalized linear model was fitted to the pooled data to infer the influence of shelter location and distance to the seed source on the process. Shelter location entered the model as a factor $\left(\operatorname{loc}_{i k s t}\right)$ of four levels accounting for the four spatial possibilities observed in the present design. Distance of seed $i$ within an artificial shelter to a seed point $j$ in plot $k$ was included as a continuous variable $\left(\right.$ dist $\left._{i j k}\right)$. Given the nature of these data (counts), the Poisson and negative binomial error structure were attempted. For both distributions, the log link function was used. The expanded expression of this model is as follows:

$\log \left(d_{i j k s t}\right)=\lambda_{0}+\operatorname{loc}_{i k s t}+\lambda_{1}$ dist $_{i j k}$

where $d_{i j k s t}$ is the sum of all seeds $i$ placed within a given artificial shelter in plot $k$ with a closest seed point $j$, stump $s$ and tree $t . \lambda_{0-1}$ are parameters to be estimated. A sequential variable selection was carried out. The performance of the two models fitted with the two distributions was tested through the comparison of their resulting AICs. This analysis was performed using function $\mathrm{glm}$ in package stats of R 2.14 (R Development Core Team 2011).

\subsubsection{Frugivore identification}

Due to slight differences in the intervals between measurements, the number of sightings for each detected species was divided by the number of days of the corresponding interval. The resulting daily frequencies for the observed species were summed over the plots and pooled over seasons (winter: January to March; spring: April to June; summer: July to September; fall: October to December). These averaged values for the different seasons were compared graphically.

\section{Results}

\subsection{Seed removal patterns}

From a temporal perspective, most seed points were completely exploited from Oct/Nov to May/Jun in both years of the study (Fig. 1). Specifically, in 49 surveys (out of $112=$ four plots $\times 28$ visits/plot), no seeds were found at the original placement. During the warmer months, seed removal either ceased completely or was much reduced.

The seed removal model proved highly accurate, with $\mathrm{EF}=$ $68.61 \%, E=0.1171$ surviving seeds $\times(\text { seed point } \times \text { month })^{-1}$ and $\mathrm{RMSE}=10.2286$ seeds $\times(\text { seed point } \times \text { month })^{-1}$. As regards the regression between observed and predicted values, the intercept and slope parameters did not significantly differ from 0 to 1 , respectively $(F=1.0093 ; p$ value $=0.3647$ ), providing no evidence of bias in the model. At temporal level, Fig. 2 shows how the model closely mimics the pattern of seed removal.

The variance structure accounting for seed point $\times$ year random variability proved the most appropriate for the current data set in terms of AIC (Table 2). The probability $\pi$ of all seeds being removed from a seed point was explained by seed production $\left(N_{0}\right.$; linearly, no quadratic terms), drought $(D)$ and cumulative precipitation 3 months prior to predation event $(\mathrm{Pp}$ ${ }_{-3}$ ) at temporal level and proximity to trees (IPOT $t$ ) at spatial level. The probability $p$ of a single seed remaining at a seed point significantly depended on seed production (linearly) and drought at temporal level, and proximity to stumps (IPOTs) at spatial level. The sign of the parameters indicates that the higher the drought and seed production and the lower the prior precipitation, the lower the likelihood of seeds being removed. Also, seeds are expected to be harvested more rapidly in the proximity of trees and stumps. A summary of model estimates is detailed in Table 3 .

\subsection{Dispersal activity}

As regards the first experiment, all seeds recovered following release on 11 Dec 2009 had been completely exploited by rodents by 19 Jan 2010 . The fate of seeds from the second attempt (set up on 19 Jan 2010) was checked on 28 Jan, 8 Feb and $16 \mathrm{Mar} 2010$. In this case, the small number of seeds that escaped rodent predation during the first week of exposure $(11 \%)$ was either unaltered at the original position $(8 \%)$, larder-hoarded (1\%) or scattered on the ground (2\%) at short distances from the deployment point (mean distance $3.16 \mathrm{~m}$ ). Surviving seeds were mostly exploited in subsequent visits (2 remaining seeds out of 240 ). These results are detailed in Fig. 3.

In the second experiment, 1,227 seeds (out of which $79 \%$ were marked) were recovered from the artificial shelters. Of cached seeds, $89 \%$ were consumed within the boxes 
Fig. 1 Mean number of remaining seeds in the seed removal experiment (solid line), physiological drought $(D$, in $\mathrm{mm}$, dotted line) and cumulative precipitation of the three previous months ( $\mathrm{Pp}_{-3}$, in $\mathrm{cm}$, dashed line) over time for plots P1 (a), P2 (b), $\mathrm{N} 3$ (c) and N4 (d)
Fig. 2 Observed (dashed line) and predicted values from the seed removal model (solid line) of mean number of remaining seeds per seed point over time in sampling plots P1 (a), P2 (b), N3 (c) and N4 (d) a
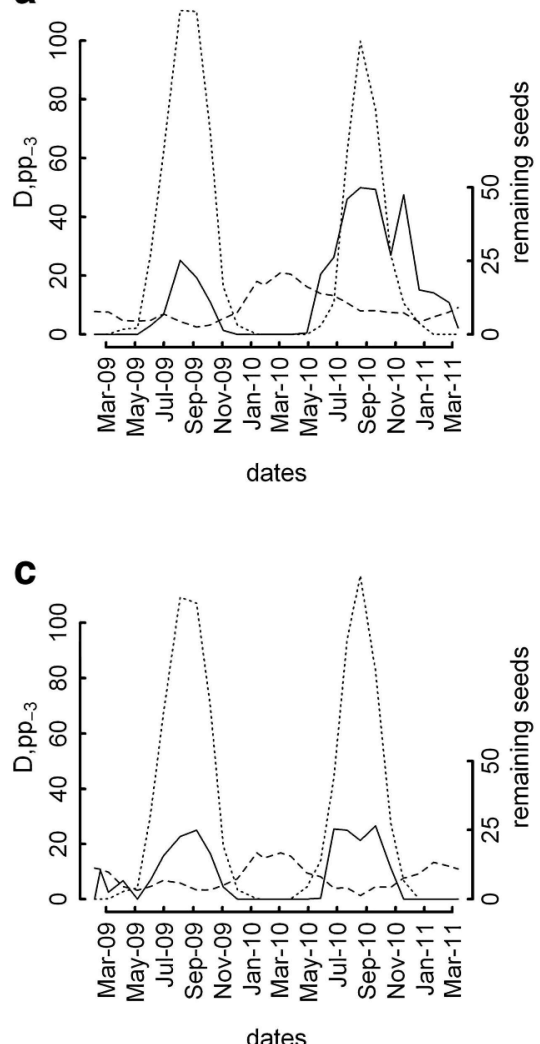

a
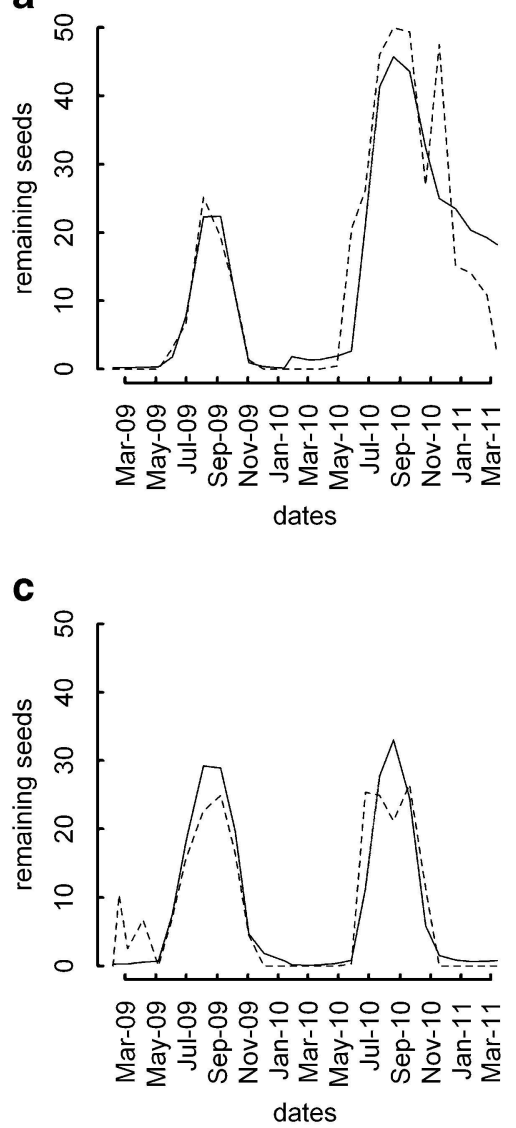

b

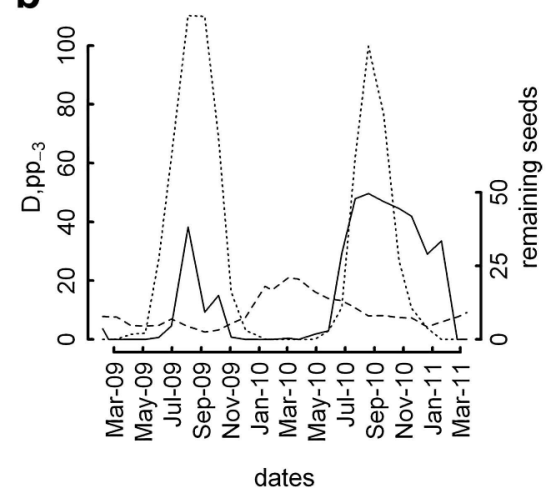

d

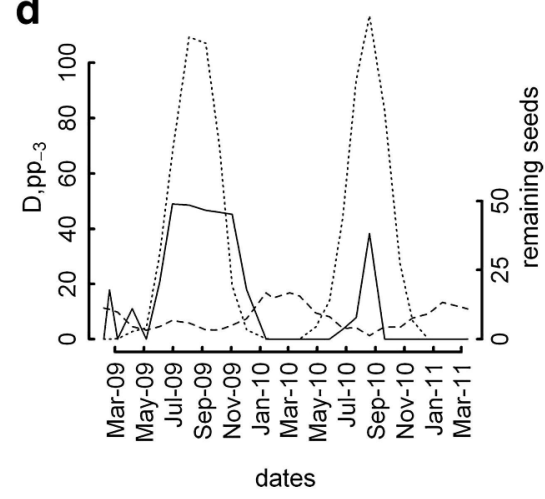

b

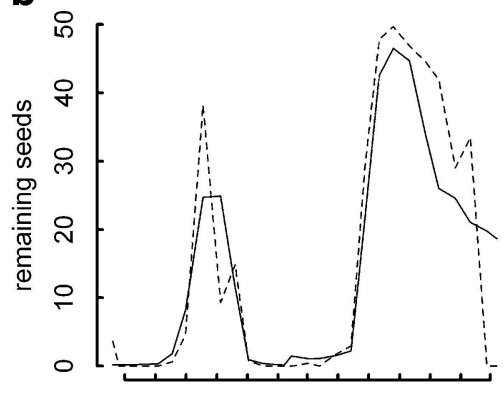

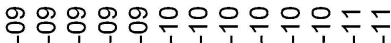

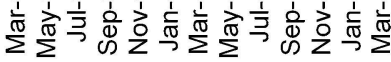
dates

d

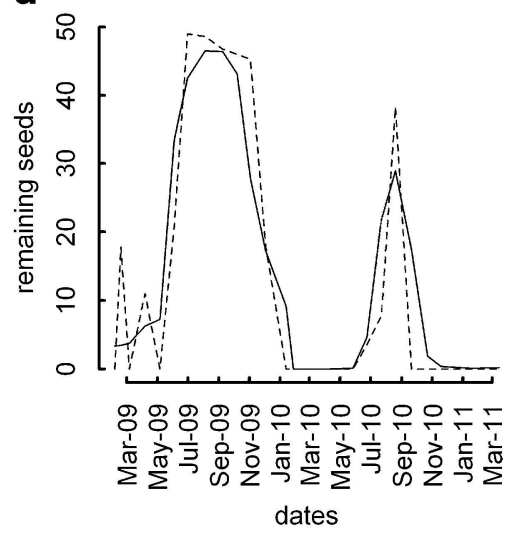


Table 2 Fit statistics for the different random structure alternatives tested in the seed removal model

\begin{tabular}{llllll}
\hline $\begin{array}{l}\text { Random } \\
\text { level }\end{array}$ & Seed point & Plot & Year $^{\mathrm{a}}$ & $\begin{array}{l}\text { Year } \times \text { seed } \\
\text { point }\end{array}$ & Year $\times$ plot \\
\hline$-2 \mathrm{LL}$ & 38,509 & 38,728 & - & 36,641 & 37,378 \\
AIC & 38,531 & 38,750 & - & 36,665 & 37,402 \\
\hline
\end{tabular}

$-2 L L$ minus twice the logarithm of the maximum likelihood estimate, AIC Akaike Information Criterium

${ }^{\text {a }}$ Lack of stable convergence

immediately after relocation. Those that survived were predated within the next month. One exception to this pattern was a shelter containing 38 seeds, which was undisturbed for two consecutive months. The number of cached seeds over time shared a common pattern from one plot to another, with higher values in autumn and spring. This information is summarized in Fig. 4. As regards the fitted model, the negative binomial distribution proved significantly more adequate than the Poisson distribution (Table 4). The parameterization of the final model indicates that seeds are less likely to be dispersed over increasing distance from the dispersal point (Table 4).

\subsection{Frugivore identification}

Overall, 1,335 videos of fauna feeding on $P$. pinea seeds were recorded. The vast majority $(80 \%)$ corresponded to the wood mouse (A. sylvaticus), whereas the azure-winged magpie (Cyanopica cooki Bonaparte) was observed in $16 \%$ of sightings. Much less frequent was the carrion crow (Corvus

Table 3 Summary of parameter estimates and significance for the selected seed removal model, including variance components of the random effects

\begin{tabular}{lccccc}
\hline Covariate & \multicolumn{2}{l}{ Occurrence of zero counts $(\beta)$} & & \multicolumn{2}{l}{ Abundance of survival $(\gamma)$} \\
\cline { 2 - 3 } \cline { 5 - 6 } & Estimate & $p$ value & & Estimate & $p$ value \\
\hline Intercept & 1.9769 & $<0.0001$ & & -0.9589 & $<0.0001$ \\
$N_{0}$ & -0.6301 & $<0.0001$ & & 0.2946 & $<0.0001$ \\
$D_{l}$ & -0.0547 & $<0.0001$ & & 0.0164 & $<0.0001$ \\
Pp$_{l-3}$ & 1.8830 & 0.0024 & & - & - \\
${\text { IPOT } t_{j}}^{\text {IPOT }}$ & 0.0087 & 0.0003 & & - & - \\
$\sigma_{j}^{2}$ & - & - & -0.6410 & $<0.0001$ \\
$\sigma_{u}^{2}$ & 1.5904 & - & - & - \\
$\sigma_{u v}$ & - & - & & 1.1562 & - \\
\hline
\end{tabular}

$N_{0}$ variable linked to seed dispersal, $D_{l}$ physiological drought, $P p_{l-3}$ cumulative precipitation of the three previous months, IPOTt and IPOTS tree and stump IPOT indexes, $\sigma^{2}{ }_{u}$ and $\sigma^{2}{ }_{v}$ estimated variances associated to the random intercepts (see point $\times$ year level), $\sigma_{u v}$ covariance between both random effects corone $\mathrm{L} . ; 4 \%$ ) and the common crossbill (Loxia curvirostra L.; $<1 \%$ ). Frequencies changed seasonally, with a minimum for $A$. sylvaticus in summer, the opposite being the case for C. cooki (Fig. 5). C. corone mostly appeared in spring. From a behavioural perspective, $A$. sylvaticus normally took only few seconds to select a single targeted seed, which was either consumed in situ or removed from the field of vision of the cameras. Contrastingly, birds always took several seeds to a different location and took longer to make their selection.

\section{Discussion}

\subsection{Seed removal patterns}

In the current study, we modelled removal of $P$. pinea seeds by A. sylvaticus. Given the present findings on a scarce A. sylvaticus dispersal activity, the seed removal model can be effectively considered a seed predation model. In accordance with our hypothesis, this model shows that seed predation is indirectly controlled by climate through two mechanisms. On the one hand, water availability accounts for within-year seed predation rates, leading to a 'safe' period during the months of water shortage. The reason for this is may be the strong dependence of $A$. sylvaticus populations on short-term prior precipitation conditions: these conditions are in turn a surrogate of primary productivity (Díaz et al. 2010). Dependence on climatic conditions is also revealed by the significant influence of drought intensity, probably reflecting the additional effect of the extreme conditions of Central Spain on food limitation. On the other hand, A. sylvaticus proved highly sensitive to the occurrence of masting events, a climate-mediated process in P. pinea (Calama et al. 2011; Mutke et al. 2005). The resulting parameterization of seed production in the model indicates that there is a greater chance of seeds escaping predation with increasing seed production. This supports the predator satiation hypothesis (Janzen 1974; Salisbury 1942), which is expected in low diversity plant communities where masting occurs (Nilsson and Wastljung 1987; Homma et al. 1999) and where predation predominates over animal-mediated dispersal (Hulme and Hunt 1999; Vander Wall 2002), as is clearly the case in our study. A predator control based on these two mechanisms has been identified in alpine ecosystems, enhancing fitness in European larch (Poncet et al. 2009), which suggests that the described pattern may be common, at least in limiting environments. In the case of $P$. pinea, the 'safe' period resulting from this strategy and the time where germination is possible (early fall) overlap (Manso et al. 2013a, b). However, germination conditions are highly strict and their timing may vary every year (Manso et al. 2013b). As a result, predation may seriously limit subsequent establishment in years of late germination. 


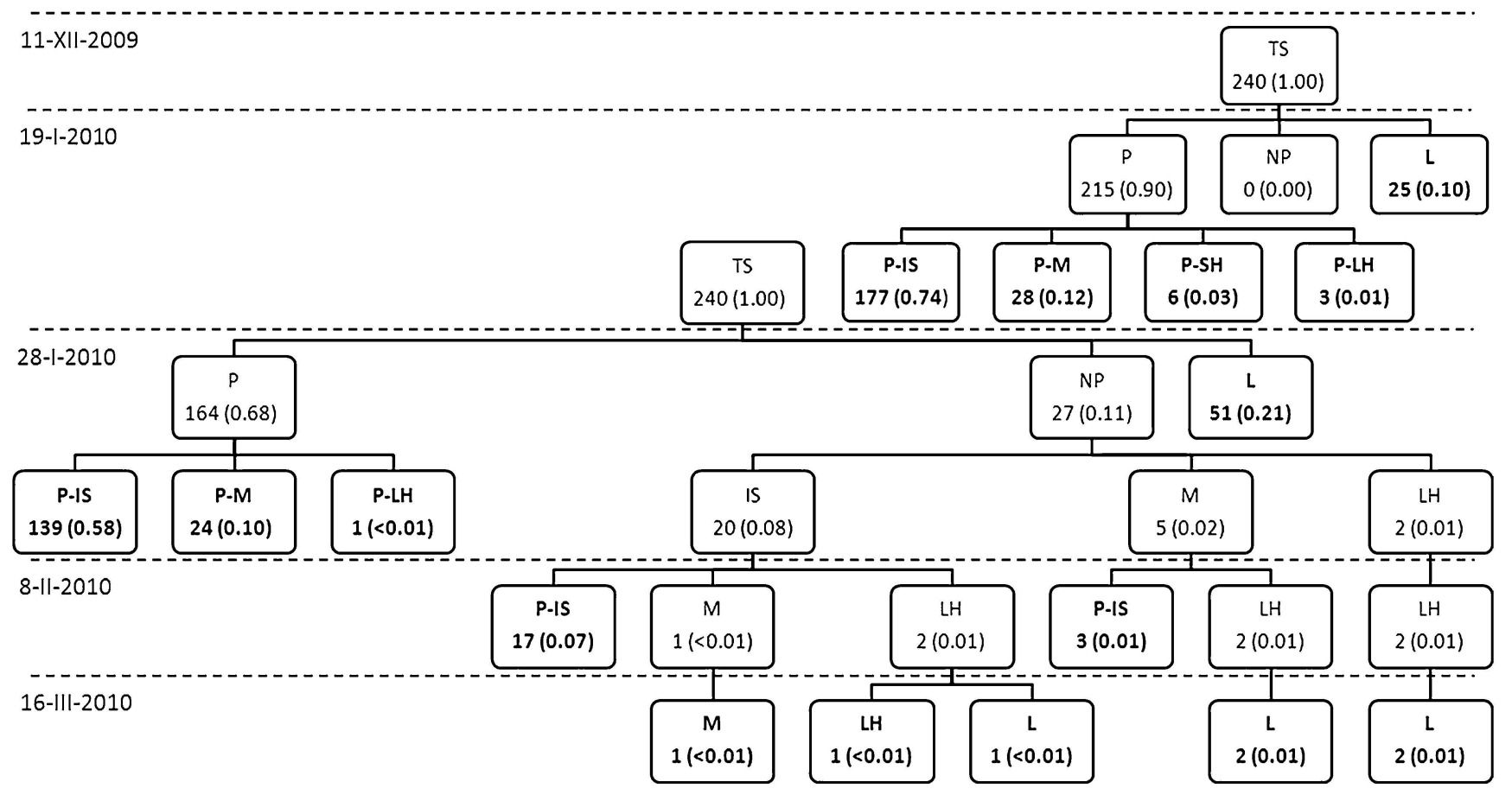

Fig. 3 Results of the seed fate experiment. Each box represents a specific state for a particular number of seeds and specific date (left). In brackets, the corresponding proportion over the total. Possible states: TS total seeds, $P$ predated, $N P$ no predated, $L$ lost, $P-I S$ predated in situ, $P-M$

reMoved and Predated, $P$-SH scatter-hoarded and predated, $P$ - $L H$ larderhoarded and predated, IS in situ, $M$ reMoved, LH larder-hoarded. In bold, terminal states

From a spatial perspective, $A$. sylvaticus predation was more intense near to seed sources, as suggested in our second hypothesis. As a consequence of a higher predation nearby trees, recruitment might have been expected at relatively large distances from seed sources (Janzen-Connell hypothesis; Connell 1971; Janzen 1970). However, Calama et al. (2012) identified a clumped distribution of 1-year-old $P$. pinea seedlings beneath the tree crowns (one crown radii), when the maximal dispersal distance is two crown radii (Manso et al. 2012). This fact suggests that the effect of $A$. sylvaticus near the trees is not strong enough to qualitatively alter the $P$. pinea seed shadow. This fact can be regarded as a consequence of the Hubbell hypothesis (Hubbell 1980) and it is ecologically consistent with further findings of Calama et al. (2013), who stated that seedling survival after the first year was also higher under the canopy. Seeds were also more rapidly predated in the proximity of the potential natural shelters identified (stumps). This finding is consistent with those reported in other studies reflecting the preference of $A$. sylvaticus for protected feeding areas (Fedriani and Manzaneda 2005; Hulme 1997).
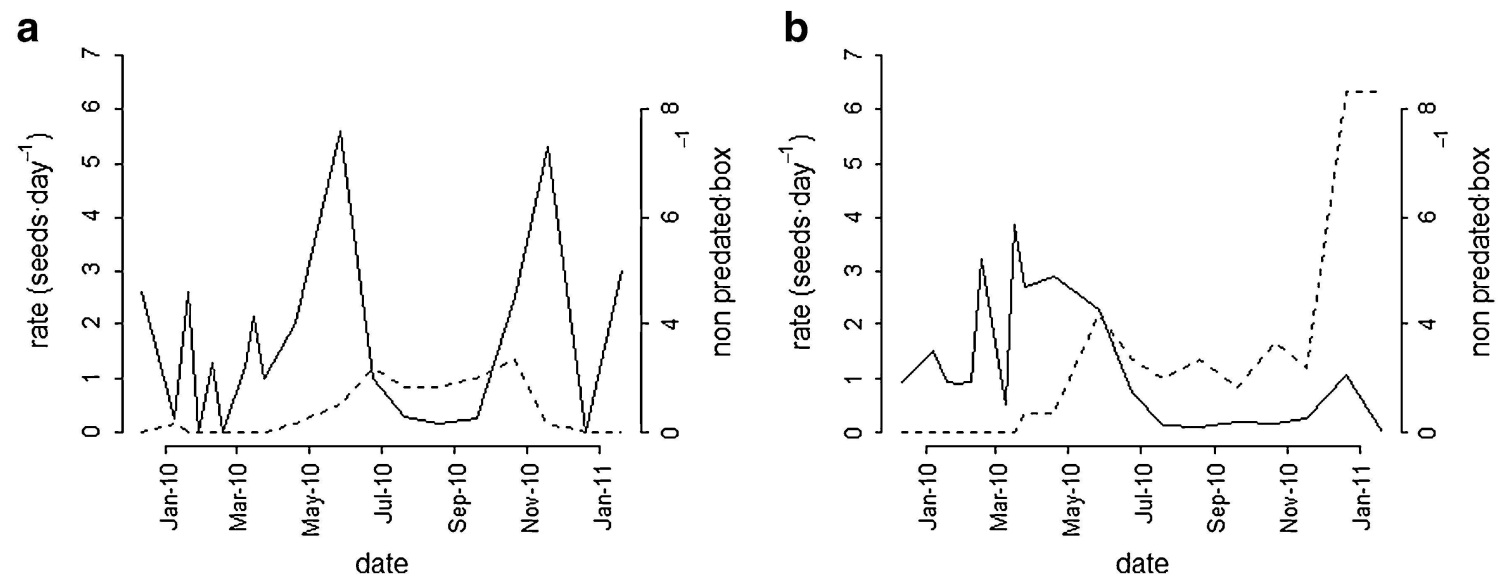

Fig. 4 Monthly rate of cached seeds (solid lines), pooled over plots; and average number of non-predated seeds per box in plots. Graphic (a) corresponds to plot P1 and graphic (b) to plot N3 
Table 4 Selection process for the seed fate model

\begin{tabular}{|c|c|c|c|c|c|}
\hline \multirow[t]{2}{*}{ Variable/statistic } & \multicolumn{2}{|c|}{ Poisson model } & \multicolumn{2}{|c|}{ Negative binomial model } & \multirow[t]{2}{*}{ Parameter value } \\
\hline & 1 & 2 & 1 & 2 & \\
\hline Intercept & $<0.0001$ & $<0.0001$ & $<0.0001$ & $<0.0001$ & 4.6049 \\
\hline $\operatorname{loc}_{i k s t, 2}$ & 0.0007 & - & 0.5200 & - & - \\
\hline $\operatorname{loc}_{i k s t, 3}$ & 0.2181 & - & 0.8060 & - & - \\
\hline $\operatorname{loc}_{i k s t, 4}$ & 0.0371 & - & 0.9650 & - & - \\
\hline dist $_{i j k}$ & $<0.0001$ & $<0.0001$ & 0.2730 & 0.00859 & -0.1517 \\
\hline$\theta$ & $1 *$ & $1^{*}$ & 1.248 & 1.222 & 1.222 \\
\hline$-2 \mathrm{LL}$ & 868.73 & 888.07 & 229.90 & 230.46 & - \\
\hline $\mathrm{AIC}$ & 878.73 & 898.07 & 241.9 & 236.46 & - \\
\hline
\end{tabular}

$l o c_{i k s t} 4$-level factor accounting for seed location in regard to trees and stumps; dist $t_{j i k}$ distance from seed location to the nearest seed station; $\theta$ parameter modelling overdispersion: when set fixed to $1\left(^{*}\right)$ a Poisson distribution is used; otherwise, a negative binomial distribution is utilized; $-2 L L$ minus twice the logarithm of the maximum likelihood estimate; AIC the Akaike Information Criterium

\subsection{Dispersal activity}

It has been reported that masting promotes animalmediated seed dispersal because hoarding animals are able to cache excessive amounts of food in order to withstand unfavourable periods (Vander Wall 2002). In accordance with our hypothesis, no evidence of such behaviour was detected in our experiments. This fact supports the results of other studies conducted on masting species in the Iberian Peninsula (Gómez et al. 2003, 2008; Hulme 1997). The reason might be that the seed dispersal period in $P$. pinea (warm period) is immediately followed by the favourable period for the rodent species (colder, wet period) (Díaz et al. 2010; Torre et al. 2002). Consequently, A. sylvaticus would not need to cache pine nuts to withstand the subsequent winter period.

Despite the observed limited extent of animal-mediated dispersal, some conclusions can be drawn on the effectiveness of the few seeds dispersed. Scatter-hoarding of $P$. pinea seeds seems to be a rarely used mechanism in A. sylvaticus, those seeds being subject of rapid pilfering and immediate consumption (Hulme 2002). Larderhoarding was much more frequent. However, this mechanism is probably less effective: on the one hand, seeds in such hoards were rapidly consumed; on the other hand, the high density of seeds in caches that escaped predation usually leads to the occurrence of unviable seedlings due to interspecific competition (Gómez et al. 2003; Hulme 2002). Furthermore, the model fitted using the artificial shelter data indicates that $A$. sylvaticus only larder-hoards up to very short distances, displaying no particular habitat preference. This fact suggests that the impact on final seedling shadow would be of little importance.

\subsection{Frugivore identification}

As hypothesized, corvids act as frugivores of $P$. pinea. Most of these visits coincided with the dispersal period of $P$. pinea. This seasonal pattern along with the fact that corvids never ate seeds in situ may indicate that these birds were dispersing pine nuts, presumably attracted by seed abundance (Vander Wall 2002). In contrast, a decrease in A. sylvaticus individuals was observed, confirming the rodent population reduction during the dry period.

Although beyond the scope of this study, the relatively high proportion of seeds used by corvids $(20 \%)$ outlines the importance of these species from an ecological viewpoint in

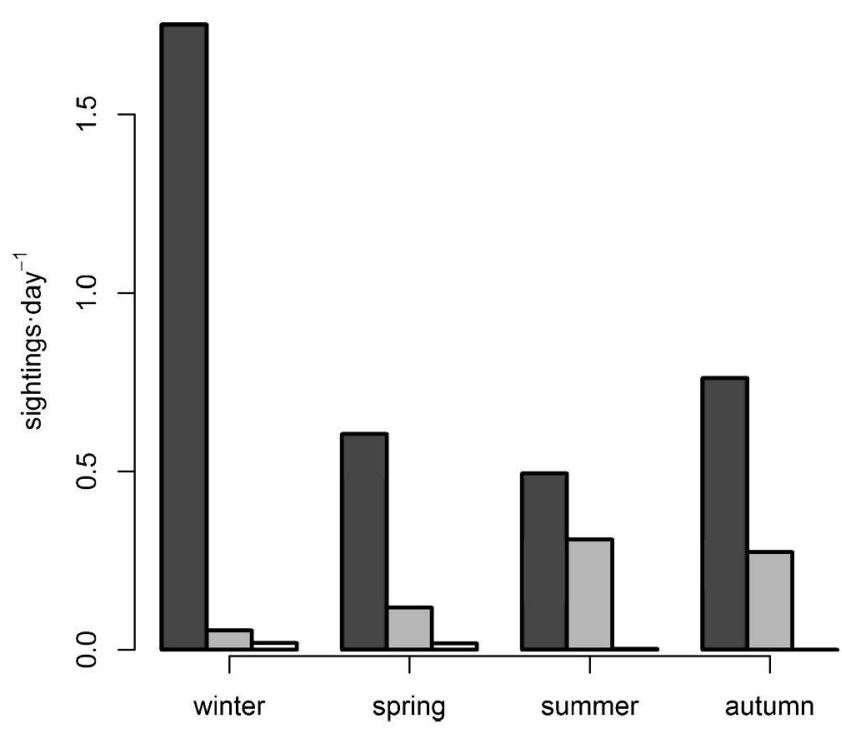

Fig. 5 Frequencies of daily animal sightings pooled over seasons. Dark, medium and light grey bars represent Apodemus sylvaticus, Cyanopica cyanus and Corvus corone values, respectively 
the system. Nevertheless, the survival of bird-dispersed seeds may depend in turn on rodent activity, as they typically hoard shallow caches easily accessible to rodents (Vander Wall and Balda 1977).

\section{Conclusions}

Survival of $P$. pinea seeds strongly depends on the length and intensity of the dry period together with masting occurrence, the main factors controlling $A$. sylvaticus activity. The timing of these events is essential for subsequent establishment. A. sylvaticus dispersal activity is not important, and it is not though to modify the seed shadow. Other frugivores, such as corvids, may be of some relevance in this respect.

\section{References}

Andersen AN (1987) Effects of seed predation by ants on seedling densities at a woodland site in SE Australia. Oikos 48:171-174

Calama R, Madrigal G, Manso R, Garriga E, Gordo FJ, Pardos M (2012) Germinación, emergencia y supervivencia de regenerado en Pinus pinea L. In: Gordo FJ, Calama R, Pardos M, Bravo F, Montero G (ed) La regeneración natural de Pinus pinea L. y Pinus pinaster Ait. en los arenales de la Meseta Castellana. Instituto Universitario de Investigación en Gestión Forestal Sostenible. Universidad de Valladolid-INIA. Valladolid

Calama R, Montero G (2006) Cone and seed production from stone pine (Pinus pinea L.) stands in Central Range (Spain). Eur J For Res 126: 23-35. doi:10.1007/s10342-005-0100-8

Calama R, Mutke S, Tomé J, Gordo J, Montero G, Tomé M (2011) Modelling spatial and temporal variability in a zero-inflated variable: the case of stone pine (Pinus pinea L.) cone production. Ecol Model 222:606-618. doi:10.1016/j.ecolmodel.2010.09.020

Calama R, Puértolas J, Madrigal G, Pardos M (2013) Modeling the environmental response of leaf net photosynthesis in Pinus pinea L. natural regeneration. Ecol Model 251:9-21. doi:10.1016/j. ecolmodel.2012.11.029

Castro J, Gómez JM, García D, Zamora R, Hodar JA (1999) Seed predation and dispersal in relict Scots pine forests in southern Spain. Plant Ecol 115-123

Connell JH (1971) On the role of natural enemies in preventing competitive exclusion in some marine animals and in rain forest trees. In Boer P, Graadwell G (ed) Dynamics of numbers in populations (Proceedings of the Advanced Study Institute, Osterbeek 1970).
Centre for Agricultural Publication and Documentation. Wageningen

De Steven D (1982) Seed production and seed mortality in a temperate forest shrub (witch-hazel, Hamamelis virginiana). $\mathrm{J}$ Ecol 70:437443

Díaz M, Torre I, Arrizabalaga A (2010) Relative roles of density and rainfall on the short-term regulation of Mediterranean wood mouse Apodemus sylvaticus populations. Acta Theriol (Warsz) 55:251260. doi:10.4098/j.at.0001-7051.046.2009

Fedriani JM, Manzaneda AJ (2005) Pre- and postdispersal seed predation by rodents: balance of food and safety. Behav Ecol 16:1018-1024. doi: $10.1093 /$ beheco/ari082

Gandullo JM (1994) Climatología y ciencia del suelo. Fundación Conde del Valle de Salazar. Madrid

Gómez J, García D, Zamora R (2003) Impact of vertebrate acorn- and seedling-predators on a Mediterranean Quercus pyrenaica forest. For Ecol Manag 180:125-134. doi:10.1016/S0378-1127(02)00608-4

Gómez JM, Puerta-Piñero C, Schupp EW (2008) Effectiveness of rodents as local seed dispersers of Holm oaks. Oecologia 155:529-537. doi: 10.1007/s00442-007-0928-3

González-Rodríguez V, Villar R (2012) Post-dispersal seed removal in four Mediterranean oaks: species and microhabitat selection differ depending on large herbivore activity. Ecol Res 27:587-594. doi:10. 1007/s11284-012-0927-7

Hall DB (2000) Zero-inflated Poisson and binomial regression with random effects: a case study. Biometrics 56:1030-1039. doi:10. 1111/j.0006-341X.2000.01030.x

Herrera CM (1995) Dispersal systems in the Mediterranean: ecological, evolutionary, and historical determinants. Annu Rev Ecol Syst 26: 705-727. doi:10.1146/annurev.es.26.110195.003421

Holling CS (1959a) Some characteristics of simple types of predation and parasitism. Can Entomol 91:385-398. doi:10.4039/Ent91385-7

Holling CS (1959b) The components of predation as revealed by a study of small-mammal predation of the European pine sawfly. Can Entomol 91:293-320. doi:10.4039/Ent91293-5

Hubbell SP (1980) Seed predation and the coexistence of tree species in tropical forests. Oikos 35:214-229

Hulme PE (1997) Post-dispersal seed predation and the establishment of vertebrate dispersed plants in Mediterranean scrublands. Oecologia 111:91-98. doi:10.1007/s004420050212

Hulme PE (2002) Seed-eaters: seed dispersal, destruction and demography. In: Levey DJ, Silva WR, Galetti M (eds) Seed dispersal and frugivory: ecology, evolution and conservation. $\mathrm{CAB}$ International, Wallingford

Hulme PE, Hunt MK (1999) Rodent post-dispersal seed predation in deciduous woodland: predator response to absolute and relative abundance of prey. J Anim Ecol 68:417-428. doi:10.1046/j.13652656.1999.00294.x

Homma K, Akashi N, Abe T, Hasegawa M, Harada K, Hirabuki Y, Irie K, Kaji M, Miguchi $H$, Mizoguchi N, Mizunaga $H$, Nakashizuka T, Natume S, Niiyama K, Ohkubo T, Sawada S, Sugita H, Takatsuki S, Yamanaka N (1999) Geographical variation in the early regeneration process of Siebold's Beech (Fagus crenata BLUME) in Japan. Plant Ecol 140: 129-138

Janzen DH (1970) Herbivores and the number of tree species in tropical forests. Am Nat 104:501-528

Janzen DH (1974) Tropical blackwater rivers, animal and mast fruiting by the Dipterocarpaceac. Biotropica 4:69-103

Jordano P (1992) Fruits and frugivory. In: Fenner M (ed) Seeds: the ecology of regeneration in natural plant communities. $\mathrm{CAB}$ International, Wallingford

Juliano SA (2001) Non-linear curve-fitting: predation and functional response curves. In: Scheiner S, Gurevitch J (eds) Design and analysis of ecological experiments. Chapman \& Hall, New York

Kuuluvainen T, Pukkala T (1989) Simulation of within-tree and betweentree shading of direct radiation in a forest canopy: effect of crown 
shape and sun elevation. Ecol Model 49:89-100. doi:10.1016/0304 3800(89)90045-8

Manso R, Calama R, Madrigal G, Pardos M (2013a) A silvicultureoriented spatio-temporal model for germination in Pinus pinea L. in the Spanish Northern Plateau based on a direct seeding experiment. Eur J For Res 132:969-982. doi:10.1007/s 10342-013-0724-Z

Manso R, Fortin M, Calama R, Pardos M (2013b) Modelling seed germination in forest tree species through survival analysis. The Pinus pinea L. case study. For Ecol Manag 289:515-524. doi:10. 1016/j.foreco.2012.10.028

Manso R, Pardos M, Keyes CR, Calama R (2012) Modelling the spatiotemporal pattern of primary dispersal in stone pine (Pinus pinea L.) stands in the Northern Plateau (Spain). Ecol Model 226:11-21. doi: 10.1016/j.ecolmodel.2011.11.028

Montgomery DC, Peck EA, Vining GG (1992) Introduction to linear regression analysis. Wiley, New York

Mutke S, Gordo J, Gil L (2005) Variability of Mediterranean Stone pine cone production: yield loss as response to climate change. Agric For Meteorol 132:263-272. doi:10.1016/j.agrformet.2005.08.002

Nilsson, SG, Wästljung, U (1987) Seed predation and cross-pollination in mast-seeding beech (Fagus sylvatica) patches. Ecology 68:260-265

Poncet BN, Garat P, Manel S, Bru N, Sachet J-M, Roques A, Despres L (2009) The effect of climate on masting in the European larch and on its specific seed predators. Oecologia 159:527-537. doi:10.1007/ s00442-008-1233-5

Puerta-Piñero C, Gómez JM, Schupp EW (2010) Spatial patterns of acorn dispersal by rodents: do acom crop size and ungulate presence matter? Oikos 119:179-187. doi:10.1111/j.1600-0706. 2009.17793.x
R Development Core Team (2011) R: a language and environment for statistical computing. Foundation for Statistical Computing, Vienna, Austria

Sagnard F, Pichot C, Dreyfus P, Jordano P, Fady B (2007) Modelling seed dispersal to predict seedling recruitment: recolonization dynamics in a plantation forest. Ecol Model 203:464-474. doi:10.1016/j. ecolmodel.2006.12.008

Salisbury EJ (1942) The reproductive capacity of plants. Bell, London

Schupp EW (1995) Seed-seedling conflicts, habitat choice, and patterns of plant recruitment. Am J Bot 82:399-409

Schupp EW, Fuentes M (1995) Spatial patterns of seed dispersal and the unification of plant population ecology. Ecoscience 2:267-275

Sork VL (1993) Evolutionary ecology of mast-seeding in temperate and tropical oaks (Quercus spp.). Vegetatio 108:133-147

Thornthwaite CW, Mather JR (1957) Instructions and tables for computing potential evapotranspiration and the water balances. Climatology 10:181-311

Torre I, Arrizabalaga A, Diaz M (2002) Ratón de campo (Apodemus sylvaticus L.). Galemys 14

Vander Wall SB (2002) Masting in animal-dispersed pines facilitates seed dispersal. Ecology 83:3508-3516. doi:10.1890/0012-9658(2002) 083[3508: MIADPF]2.0.CO;2

Vander Wall SB, Balda RP (1977) Coadaptations of the Clark's nutcracker and the pinon pine for efficient seed harvest and dispersal. Ecol Monogr 47:89. doi:10.2307/1942225

Wu H-I, Sharpe PJH, Walker J, Penridge LK (1985) Ecological field theory: a spatial analysis of resource interference among plants. Ecol Model 29:215-243. doi:10.1016/0304-3800(85) 90054-7 